\title{
AARP Members in Rhode Island: Interests, Concerns \& Experiences
}

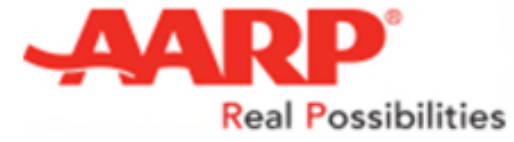

Financial

Social Security is the top economic concern for the majority of AARP members in Rhode Island.

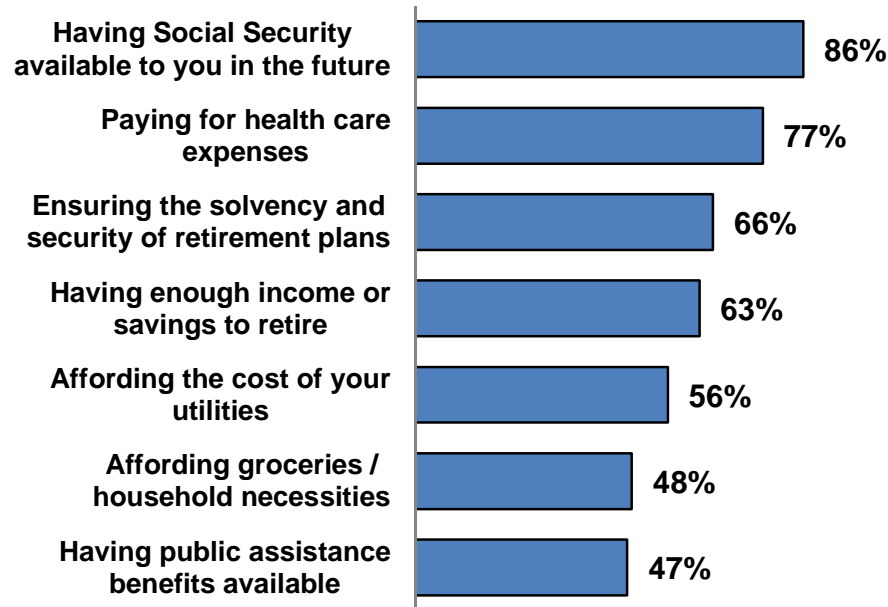

Many members experienced major life events in the last 2 years that impact their economic security:

- Reduction in income (35\%)

- Reduction in savings or assets (31\%)

- Started claiming Social Security benefits (18\%)

- Debt problems (13\%)

\section{Most AARP members are concerned about consumer fraud or identity theft $(74 \%)$.}

Members in Rhode Island are also extremely or very concerned about protecting themselves against unfair/deceptive financial practices $(62 \%)$, and having online security and safety (52\%).

\section{Work Retirement}

More than half of Rhode Island members are retired $(52 \%)$, and many workers are interested in planning for retirement.

Fewer than half of Rhode Island members are still in the workforce. In the past 2 years, $13 \%$ lost a job, $7 \%$ started a new job, and $2 \%$ started their own business. Overall, $33 \%$ of members in Rhode Island are concerned about job opportunities in their community and $28 \%$ are concerned about facing age discrimination. Still, many are quite interested in finding new ways to make money and improve their careers.

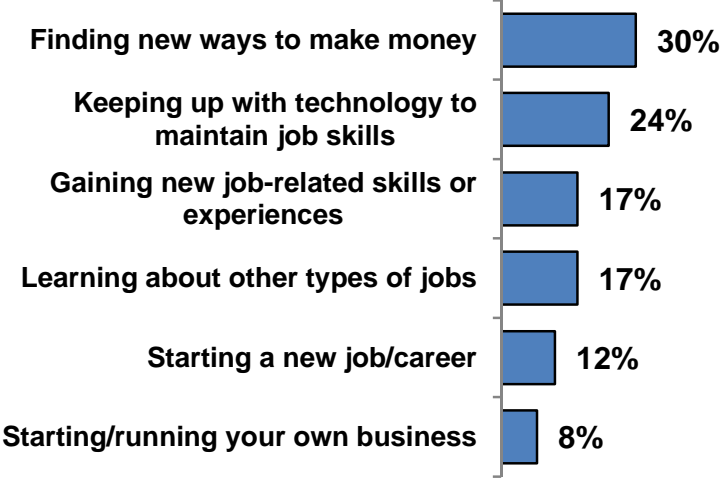

In the past 2 years, $19 \%$ of members started retirement. More than a quarter are concerned about having to postpone retirement (28\%). On average, Rhode Island members would like to retire at age 67, but realistically think it will be closer to age 69 . In preparing for retirement, members are interested in:

- Planning what to do in retirement (39\%)

- Planning financially for retirement $(38 \%)$

- Learning about retirement alternatives (33\%)

- Having flexible work arrangements (25\%)

${ }^{1}$ Responses of "Extremely concerned," "Very concerned," "Extremely interested" and "Very interested" were used to determine the "concern" and "interest" values. 


\section{Health}

Brain health is a top interest and concern for members in Rhode Island.

Only $9 \%$ of members report experiencing memory loss or cognitive impairment in the past 2 years, but the majority is interested in taking steps to stay mentally sharp.

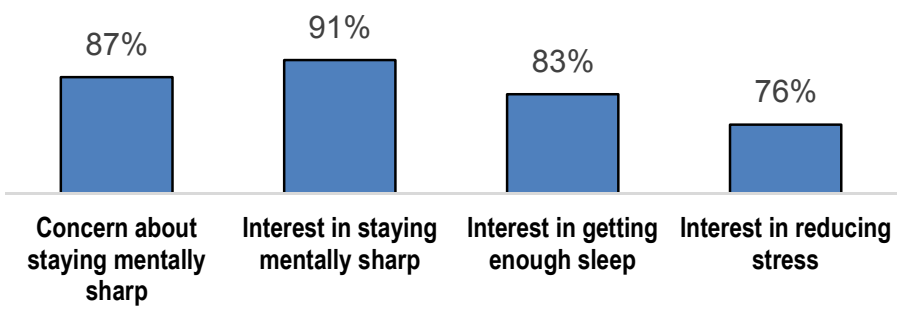

Most AARP members are interested in staying healthy, and are concerned about having health insurance to help them do so.

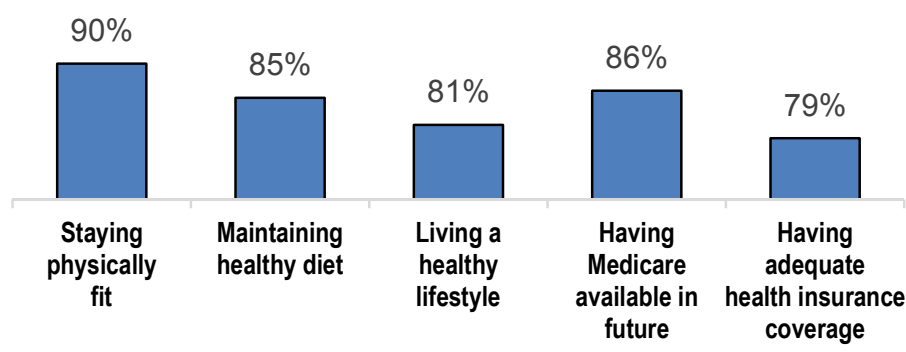

Seven in ten (69\%) members say they are concerned about declining physical health or chronic conditions.

Members in Rhode Island are concerned about their health and some have experienced health declines in the past two years:

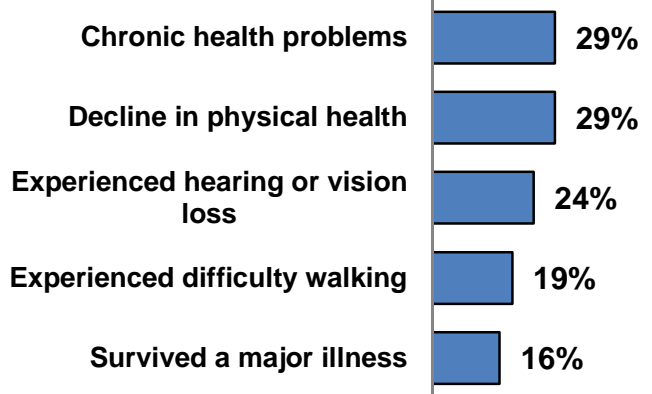

\section{Family \& Independent Living}

The majority of members are interested in spending time with their families and enjoying personal interests:

- Spending time with family and friends (84\%)

- Spending time on hobbies and personal interests $(68 \%)$

- Traveling (65\%)

- Learning new things (64\%)

- Finding local entertainment activities that are fun and affordable $(63 \%)$

- Setting and/or achieving personal goals (54\%)

Rhode Island members have the following concerns related to remaining independent as they grow older:

Staying in your own home as you get older

$66 \%$

Continuing to drive or get around as you get older

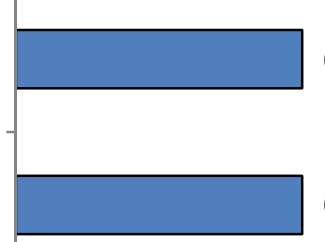

$66 \%$

Having long-term care or home health services available

Paying for long-term care (nursing home, home health services, etc.)

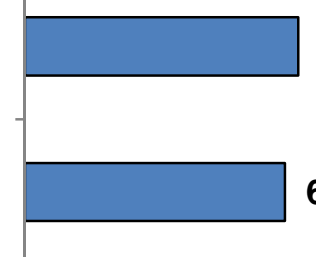
$63 \%$ $60 \%$

\section{About one-third of Rhode Island members are caregivers.}

About four in ten (42\%) Rhode Island members are concerned about providing help for a loved one. Currently, about one-third (35\%) are caregivers and $3 \%$ have parents living with them. In the past 2 years:

- $5 \%$ have had a family member move in with them

- $9 \%$ have had a parent or older relative move into a nursing home 


\section{Demographic Profile of Rhode Island Members}
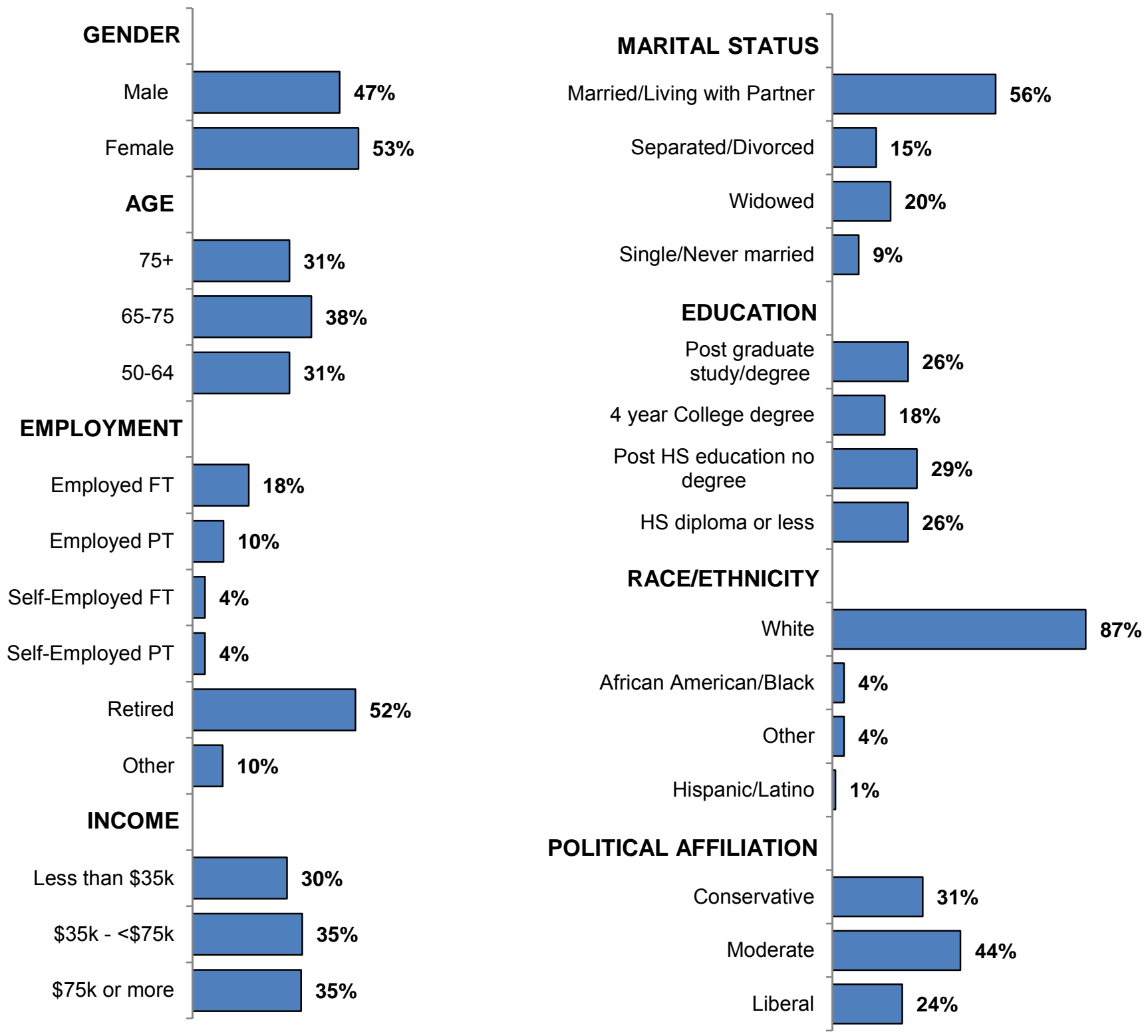

\section{Methodology}

AARP contacted a stratified random sample of 140,000 members in all 50 states, District of Columbia, Puerto Rico, and U.S. Virgin Islands, inviting them to participate in this survey, either by mail or online between March and June 2016. A total of 22,839 members completed and returned surveys for a response rate of $16 \%$.In Rhode Island, 2,499 members were contacted with 349 completing and returning surveys. The overall response rate for Rhode Island was $14 \%$. The margin of error for Rhode Island respondents is \pm 5.3 percent. A full methodology report can be found at www.aarp.org/2016MOS.

For more information, please contact Cassandra Cantave, AARP Research at 202-434-3547 or e-mail ccantave@aarp.org 